\title{
China's spatial (dis)integration as a multiethnic paradox: what do the interprovincial data say?
}

Rongxing Guo

\section{Correspondence:}

guorongxingguo@yahoo.com Regional Science Association of China, Peking University, Beijing 101402, China

\begin{abstract}
Background: Compared with its surging foreign trade, China's domestic trade growth from 2000 to 2010 had been less encouraging. Then, what are the driving forces behind the dynamic pattern of China's domestic trade?

Methods: Using the gravity model of trade and China's interprovincial panel data, this paper shows that the negative effect of distance-related transactions costs on interprovincial trade tends to rise from 2000 to 2010. After constructing China's 56 ethnic groups into a single, interprovincial similarity index, I cannot find any evidence that supports the view that ethnic links should serve as a factor promoting bilateral trade.

Results: However, my estimated coefficients on 37 major ethnic groups show that both positive and negative ethnic influences on trade exist in China. Specifically, 14 ethnic groups (Lahu, Qiang, Jingpo, Tu, Mongol, Manchu, Hui, Zhuang, Dongxiang, Daur, Kirgiz, She, Maonan, and Tibetan) are found to contribute to China's interprovincial trade, while five ethnic groups (Han, Va, Kazak, Dai, and Blang) tend to impede China's interprovincial trade. Conclusions: These findings will be useful for policy-makers to reappraise which of China's ethnic groups are playing the most (least) important roles in, and to introduce the optimal informal institutions into, the promotion of interprovincial economic cooperation in China.

Keywords: Domestic trade, Spatial (dis)integration, Interprovincial ethnic linkage, Province, China
\end{abstract}

\section{Background}

The first decade of the twenty-first century was unusual to China. Promoted by its entry into the World Trade Organization (WTO) on December 11, 2001, China's economic growth has significantly driven by its remarkable performance in foreign trade. WTO data shows that China's exports and imports enjoyed the average annual growth rates of $18 \%$ and $16 \%$ from 2000 to 2010, respectively, much higher than the average annual growth rate of the global trade volume in the same period, which was only $3 \%{ }^{1}$ In 2000, for example, China was the seventh leading exporter and eighth largest importer of merchandise trade. Since 2001, China has steadily increased its share of global manufactured exports. Notwithstanding the global reductions in trade, which resulted from the US financial crisis in 2008, China replaced Germany as the world's largest exporting nation in 2009. In 2010, China continued to be the leading merchandise exporter (US\$1.58 trillion, or $10.4 \%$ of world exports), followed by the USA (8.4 \% of world exports), Germany (8.3\% of world exports), and Japan (5.1\% of world exports). ${ }^{2}$ 
When looking inside China, however, one can only find less encouraging news. For example, compared with its surging foreign trade as mentioned above, which has increased by more than four (for exports) or three (for imports) times from 2000 to 2010, China's domestic trade has only achieved a growth of $86.26 \%$ during the same period (see Table 1). This means that China's domestic trade-both intra-provincial and interprovincial-has only had an average annual growth rate of about $6 \%$ from 2000 to 2010. Frankly speaking, this may not have been treated as a low figure in many other countries during that period of time. However, compared with its $16-18 \%$ of annual foreign trade growth rate and $10 \%$

Table 1 Changes of China's domestic and interprovincial trade from 2000 to 2010

\begin{tabular}{|c|c|c|c|c|c|c|}
\hline \multirow{2}{*}{$\begin{array}{l}\text { Provincial } \\
\text { economy }\end{array}$} & \multicolumn{3}{|c|}{ Domestic trade (thousand tons) } & \multicolumn{3}{|c|}{ Ratio of interprovincial trade (\%) } \\
\hline & 2000 & 2010 & Change (\%) & 2000 & 2010 & Change (\%) \\
\hline Anhui & 6087 & 12,092 & 98.65 & 56.84 & 47.93 & -8.91 \\
\hline Beijing & 2612 & 1571 & -39.85 & 72.21 & 95.23 & 23.02 \\
\hline Chongqing & 1613 & 2197 & 36.21 & 56.79 & 65.95 & 9.16 \\
\hline Fujian & 2475 & 3704 & 49.66 & 46.22 & 53.48 & 7.26 \\
\hline Gansu & 3236 & 6186 & 91.16 & 52.10 & 61.27 & 9.17 \\
\hline Guangdong & 4521 & 7505 & 66.00 & 74.70 & 79.72 & 5.02 \\
\hline Guangxi & 2815 & 6109 & 117.02 & 67.10 & 75.82 & 8.72 \\
\hline Guizhou & 3585 & 7991 & 122.90 & 69.29 & 82.98 & 13.69 \\
\hline Hainan & 311 & 542 & 74.28 & NA & 10.89 & NA \\
\hline Hebei & 11,399 & 16,481 & 44.58 & 60.61 & 56.09 & -4.52 \\
\hline Heilongjiang & 12,701 & 16,888 & 32.97 & 54.47 & 49.19 & -5.28 \\
\hline Henan & 9655 & 13,374 & 38.52 & 78.92 & 71.53 & -7.39 \\
\hline Hubei & 3937 & 5698 & 44.73 & 62.81 & 66.57 & 3.75 \\
\hline Hunan & 4668 & 5783 & 23.89 & 65.62 & 61.27 & -4.35 \\
\hline Inner Mongolia & 9171 & 37,698 & 311.06 & 69.55 & 77.00 & 7.46 \\
\hline Jiangsu & 4076 & 6372 & 56.33 & 63.67 & 85.75 & 22.08 \\
\hline Jiangxi & 2959 & 5376 & 81.68 & 57.92 & 51.95 & -5.97 \\
\hline Jilin & 5630 & 7674 & 36.31 & 60.55 & 69.53 & 8.98 \\
\hline Liaoning & 12,520 & 18,118 & 44.71 & 34.03 & 29.94 & -4.09 \\
\hline Ningxia & 1782 & 4414 & 147.70 & 73.12 & 86.45 & 13.33 \\
\hline Qinghai & 647 & 3096 & 378.52 & 81.14 & 61.66 & -19.48 \\
\hline Shaanxi & 3280 & 8836 & 169.39 & 65.95 & 69.09 & 3.15 \\
\hline Shandong & 10,585 & 18,285 & 72.74 & 52.24 & 62.67 & 10.43 \\
\hline Shanghai & 1054 & 959 & -9.01 & 89.56 & 93.53 & 3.97 \\
\hline Shanxi & 28,469 & 60,812 & 113.61 & 91.96 & 92.76 & 0.80 \\
\hline Sichuan & 5516 & 7389 & 33.96 & 46.79 & 51.59 & 4.80 \\
\hline Tianjin & 2004 & 7240 & 261.28 & 81.64 & 54.46 & -27.18 \\
\hline Tibet & & 30 & NA & & 100.00 & NA \\
\hline Xinjiang & 3353 & 6775 & 102.06 & 73.67 & 74.05 & 0.39 \\
\hline Yunnan & 2882 & 5209 & 80.74 & 59.51 & 67.92 & 8.41 \\
\hline Zhejiang & 1929 & 3806 & 97.30 & 62.10 & 41.59 & -20.51 \\
\hline All & 165,472 & 308,210 & 86.26 & 65.53 & 69.06 & 5.39 \\
\hline
\end{tabular}

(1) "Trade" only includes freight exchange via national railways. (2) NA = data are not available Source: calculated by the author based on China Association of Communications and Transportation and the National Development and Reform Commission of the People's Republic of China (2001, 2011) 
of annual gross domestic product (GDP) growth rate from 2000 to 2010, China's domestic trade performance can only but be labeled as "poor".

Even worse news comes from China's interprovincial trade performance. China's official statistics on interprovincial trade (in terms of freight exchange via national railways) are puzzling. For example, except for China's two peripheral territories (i.e., Hainan and Tibet) whose data are not available in 2000, the proportions of interprovincial trade to the total domestic trade have risen in only 17 provincial economies (i.e., Beijing, Jiangsu, Guizhou, Ningxia, Shandong, Gansu, Chongqing, Jilin, Guangxi, Yunnan, Inner Mongolia, Fujian, Guangdong, Sichuan, Shanghai, Hubei, and Shaanxi) from 2000 to 2010. By way of contrast, the proportions for the remaining provincial economies have either decreased (i.e., in Tianjin, Zhejiang, Qinghai, Anhui, Henan, Jiangxi, Heilongjiang, Hebei, Hunan, and Liaoning) or been kept almost unchanged (i.e., in Shanxi and Xinjiang) during the same period (see Table 1 for more details). ${ }^{3}$

Indeed, the above phenomenon is unusual, especially after the following facts are taken into account:

(i) Since the 1990s, there has been a significant improvement of transport infrastructures (including, inter alia, the completion of various expressways and high-speed railways across the nation) in China

(ii) Since 1999, the "Western Regional Development Policy" has been implemented by the Chinese central government in order to speed up the development of the western and central provinces by encouraging the economic cooperation between the East-West provinces

(iii) Since 2008, and as a result of the global reductions in trade, which resulted from the US financial crisis, the Chinese government has made various efforts in order to stimulate China's domestic consumption

Then, what are the driving forces behind the dynamic patterns of China's domestic trade and how to explain its interprovincial trade puzzle?

\section{Methods}

\section{Literature review}

Past studies of the determinants of spatial economic interdependence seem controversial, or at least incomplete. According to the Heckscher-Ohlin theorem, if the two factors of production are capital and labor, countries with dissimilar levels of per capita income (or, more precisely, dissimilar capital/labor ratios) will trade more than countries with similar levels (Heckscher 1919; Ohlin 1933). However, a number of empirical results indicate that the inclusion of income level as a determinant of trade contradicts the assumptions of traditional Heckscher-Ohlin theory (e.g., Linder 1961; Deardorff 1998, p. 15). In order to fill up this gap, economists have put forward new theories that base international trade on, among others, economies of scale, market imperfections, and cross-national differences in technology (e.g., Markusen 1986; Helpman 1987; Krugman 1995).

However, past studies have raised more questions than they have answered. For example, the effects of geographical proximity on trade have not been shown to fall over time. Rather, these effects have been shown to strengthen over time for 1950-1988 
(Boisso and Ferrantino 1997) and 1965-1992 (Frankel et al. 1997a). Similarly, Rauch (1999) provides no evidence that, as a result of technological innovation, declining distance-related transactions costs should have led to increased trade flows. One possibility is that these analyses exclude important explanatory variables, thereby biasing the estimates. ${ }^{4}$ To clarify related issues, it is necessary to isolate the influences of all distance-related variables on trade. In particular, the inclusion of some relevant cultural variables might allow us to gain a better understanding of the black box containing the distance-related transactions costs that affect spatial economic activities.

China has officially identified, except other unknown ethnic groups and foreigners with Chinese citizenship, 56 ethnic groups. Although the majority of China's population is of the Han nationality (which accounts for more than $90 \%$ of China's total population), the non-Han ethnic groups have a population of more than 100 million. Thanks to the easing migration policy that has been implemented since the 1980s, China's interprovincial labor flows have increased dramatically. It is noteworthy that these flows have also been conducted by people coming from the inland, ethnic-minority, areas and moving into the coastal, Han-majority areas. Consequently, China's interprovincial ethnic networks have been enhanced. As of 2010 when the Sixth National Population Census of the People's Republic of China was conducted, each of China's 31 provinces has become home to almost all ethnic groups. How have these growing ethnic networks contributed to (or impeded) China's interprovincial economic cooperation and integration?

There is a widely held view that easily observable impediments, such as transportation costs, do not adequately capture transactions costs in international trade. Trade is also reduced by hidden transaction costs associated with unobserved trade barriers. ${ }^{5}$ In addition, some studies use international panel data and find that cultural distance or dissimilarity-as proxied by, among other things, the ethnic/linguistic and religious differences across national populations-is a robust determinant of the volume of international trade (see, for example, Rauch and Trindade 2002; Noland 2005; Guiso et al. 2006; and Guo 2009, pp. 77-102).

Since the 1990s, numerous quantitative studies have examined the role that cultural factors play in international trade (e.g., Havrylyshyn and Pritchett 1991; Foroutan and Pritchett 1993; Frankel and Wei 1995; Frankel et al. 1997a; Rauch 1999; Guo 2007; Melitz 2008; Felbermayr et al. 2010). These studies used linguistic or/and religious links as one or more explanatory variables. The estimated results suggest that countries which are similar to one another have been more likely to trade with each other in the postwar period. In other words, there is evidence of cultural barriers to trade.

Indeed, trade and economic cooperation may be affected by cultural dissimilarities, as it is easier and more efficient for people with the same cultural identity (ethnicity, language, religion, or any other cultural elements) to trust and communicate each other than for those with different cultural identities. In this paper, our particular interest is to test how ethnic differences have influenced China's interprovincial trade and economic cooperation. Even though language is an effective tool of communication and that religion can provide insights into the characteristics of a culture, we would rather select ethnicity as the explanatory variable. The rationale is that most, if not all, of China's ethnic groups are identified in terms of either linguistic or religious traditions. Another reason lies in the fact that, in China, it is more difficult, if not impossible, to 
collect interprovincial panel data on linguistic and religious groups than those on ethnic groups.

The gravity model is most commonly used by international and regional economists to study trade. The classic early application of the model was by Linnemann (1966), who continued work first reported in Tinbergen (1962) and then in Pöyhönen (1963). ${ }^{6}$ Generally, a gravity model assumes that the volume of trade between any two economies will be directly proportional to the product of their economic masses (measured by GDP or GNP) and inversely proportional to the distance between them. Per capita incomes (measured by product of per capita GDPs or GNPs) have become a standard covariate in the gravity models of, for example, Eaton and Tamura (1994); Frankel et al. (1997a, b) and Rauch (1999).

\section{The model}

In this paper, our particular interest is to test how various ethnic groups have influenced China's interprovincial trade and economic cooperation. Recent gravity equations, compared to the earlier ones, have included multilateral trade resistance (MTR) terms (e.g., Feenstra 2004; Baldwin and Taglioni 2006; Head and Mayer 2013). The MTR terms arise because in a general equilibrium model, trade flows between any two provinces not only depend on trade costs between the two provinces under consideration, but also on trade costs between all other trading pairs. However, in this paper, we intend to simplify the MTR terms. The rationale is that China's domestic MTR terms, if they do exist, are much weaker than the international ones. To this end, we only add country-fixed effects to the gravity models. As noted by Adam and Cobham (2007), these effects can be thought of theoretically as approximations to MTR terms. The basic form of the gravity model to be used in our empirical analysis of interprovincial trade is as the following ${ }^{7}$ :

$$
\begin{aligned}
\ln \left(\text { TRADE }_{i j}\right)=\alpha_{0} & +\alpha_{1} \ln \left(\mathrm{GDP}_{i} \mathrm{GDP}_{j}\right)+\alpha_{2} \operatorname{lnDISTANCE} \\
i j & +\alpha_{3} \mathrm{ADJACENT}_{i j} \\
& +\alpha_{4} \ln \left(\mathrm{GDPPC}_{i} \mathrm{GDPPC}_{j}\right)+\alpha_{5} \mathrm{PD}+\beta \mathrm{ETHNIC}_{i j}
\end{aligned}
$$

In Eq. (1), "In" represents the natural logarithm; TRADE $i j$, measured in thousand tons, is the total freight exchange between provinces $i$ and $j . \mathrm{GDP}_{i} \mathrm{GDP}_{j}$ is the product of GDP (in Chinese currency) of the $i$ th and $j$ th provinces. DISTANCE $i j$ represents the distance between the geographical centers of gravity of the $i$ th and $j$ th provinces (in kilometers). ${ }^{8}$ ADJACENT $i j$ is a dummy variable, which takes the values of " 1 " for provinces $i$ and $j$ to have a common border and of "0" otherwise. $\operatorname{GDPPC}_{i} \mathrm{GDPPC}_{j}$ is the product of GDP per capita (in Chinese currency) of the $i$ th and $j$ th provinces. PD denotes a province dummy, which takes the values of " 1 " for provinces to be either a mountain-dominated or an island province (Chongqing, Guizhou, Hainan, Qinghai, Sichuan, Tibet, or Yunnan-we include these provinces since they have China's most complicated geographical conditions and therefore have the most difficulties in transportation) and of " 0 " otherwise.

ETHNIC56 $i j$ represents the extent to which the $i$ th and $j$ th provinces are ethnically linked each other (details about the measurement will be discussed in Eq. (6) in "The data" sub-section). Note that since ETHNIC56 is a comprehensive index for all of China's 
56 ethnic groups, it can only be used to derive a general pattern of correlation between interprovincial trade and ethnic linkage. If one wants to examine the role that each ethnic group plays, the gravity model can be now written as the following:

$$
\begin{aligned}
\ln \left(\mathrm{TRADE}_{i j}\right)=\alpha_{0} & +\alpha_{1} \ln \left(\mathrm{GDP}_{i} \mathrm{GDP}_{j}\right)+\alpha_{2} \ln \operatorname{LISTANCE}_{i j}+\alpha_{3} \mathrm{ADJACENT}_{i j} \\
& +\alpha_{4} \ln \left(\mathrm{GDPPC}_{i} \mathrm{GDPPC}_{j}\right)+\alpha_{5} \mathrm{PD}+\sum_{\mathrm{k}=1}^{37} \beta_{k} \mathrm{ETHNIC}_{i j k}
\end{aligned}
$$

In Eq. (2), ETHNIC $i j k$ represents the extent to which the $k$ th ethnic group is linked between the $i$ th and $j$ th provinces (details about the measurement will be discussed in Eq. (5) in "The data" section). Only 37 ethnic groups-each with a population of less than 100,000 persons (see Appendix for more detailed information)-are included in this equation.

Theoretically, cultural dissimilarity can result in both social transactions costs (a factor directly impeding trade) and "economic complementarity" (an important factor directly facilitating trade) simultaneously. As a result, the relationship between trade and cultural similarity may follow a non-linear pattern (Guo 2004, 2009, pp. 96-101). Our interest now goes to the clarification of specific cultural groups which may have different types of influences on trade with provinces differing in income levels. To go further, this paper employ a new explanatory variable: $\ln \left(\mathrm{GDPPC}_{i} \mathrm{GDPPC}_{j}\right) \mathrm{ETHNIC} 6_{i j}$. Consequently, a modified form of gravity model is written as:

$$
\begin{aligned}
\ln \left(\text { TRADE }_{i j}\right)=\alpha_{0} & +\alpha_{1} \ln \left(\mathrm{GDP}_{i} \mathrm{GDP}_{j}\right)+\alpha_{2} \operatorname{lnDISTANCE}_{i j}+\alpha_{3} \mathrm{ADJACENT}_{i j} \\
& +\alpha_{4} \ln \left(\mathrm{GDPPC}_{i} \mathrm{GDPPC}_{j}\right) \mathrm{ETHNIC}_{i j}+\alpha_{5} \mathrm{PD}+\sum_{k=1}^{37} \beta_{k} \mathrm{ETHNIC}_{i j k}
\end{aligned}
$$

In Eq. (3), the ethnicity variable is now entered into the gravity model linearly and also as a product with the natural log of per capita GDPs. Thus, the effect of an ethnic group on interprovincial trade is now allowed to exist separately and to depend on the income levels of trading partners, measured by the natural log of their per capita GDPs. As a matter of fact, since ETHNIC56 $i j$ can be written as Ethnic $_{i j 1}+$ Ethnic $_{i j 2}+\ldots+$ Ethnic $_{i j k}+\ldots+$ Ethnic $_{i j 56}$, the non-linear effects of some, if not all ethnic variables on interprovincial trade may be derived from Eq. (3).

Specifically, as for the $k$ th ethnic group $(k=1,2, \ldots, 37)$, if the estimated coefficients on Ethnic $i j k$ (that is, $\beta_{k}$ ) and on $\ln \left(\mathrm{GDPPC}_{i} \mathrm{GDPPC}_{j}\right) \mathrm{ETHNIC}_{i j}$ (that is, $\left.\alpha_{4}\right)$ have different signs (such as $\alpha_{4}<0$ and $\beta_{k}>0$; or $\alpha_{4}>0$ and $\beta_{k}<0$ ) and are statistically significant in Eq. (3), one obtains a threshold value $\left(\ln \left(\mathrm{GDPPC}_{i} \mathrm{GDPPC}_{j}\right)_{k}^{*}\right)$ by letting the firstorder differential of the dependent variable $\left(\ln \left(\mathrm{TRADE}_{i j}\right)\right.$ with respect to Ethnic $i j k$ be zero, which is:

$$
\ln \left(\mathrm{GDPPC}_{i} \mathrm{GDPPC}_{j}\right)^{*}{ }_{k}=-\beta_{k} / \alpha_{4}>0\left(\text { with } \alpha_{4}<0 \text { and } \beta_{k}>0 \text {; or } \alpha_{4}>0 \text { and } \beta_{k}<0\right) .
$$

As for the case of $\alpha_{4}<0$ and $\beta_{k}>0$ :

(i) If $\ln \left(\mathrm{GDPPC}_{i} \mathrm{GDPPC}_{j}\right)_{k}$ is smaller than $\ln \left(\mathrm{GDPPC}_{i} \mathrm{GDPPC}_{j}\right)_{k}^{*}$, the $k$ th ethnic group has a positive effect on the trade between the $i$ th and $j$ th provinces

(ii) If $\ln \left(\mathrm{GDPPC}_{i} \mathrm{GDPPC}_{j}\right)_{k}$ is larger than $\ln \left(\mathrm{GDPPC}_{i} \mathrm{GDPPC}_{j}\right)_{k}^{*}$, the $k$ th ethnic group has a negative effect on the trade between the $i$ th and $j$ th provinces. 


\section{The data}

The major task of this paper is to quantitatively investigate the sources for changes in China's spatial economic integration over time. Thus, the use of the crosssectional data from China's provincial economies in different years enables that the estimated results are not artifact of any particular time period and to allow for changes in coefficients. Generally, a decade-long period is appropriate for this kind of research because analysis for a shorter period would not reflect relevant social and economic changes, while significant changes in transportation and communication technologies would have to be accounted for if a longer one is used. Of course, a longer period is still more helpful if three or more sets of cross-sectional data are available. However, this would increase inevitably the costs in data collection. In this paper, after taking into account data availability, we select 2 years -2000 and 2010 .

The data on interprovincial trade are cited from China Communications Yearbooks (2000 and 2010). ${ }^{9}$ China's 2000 and 2010 provincial GDP and per capita GDP data are from China Statistical Yearbooks (NBS 2001, 2011). Unlike those of many Western democratic economies, China's provincial capitals usually are also the economic centers of their respective provinces. To this end, the following terms are used to express China's interprovincial geographical proximity: “distance between capitals" and "interprovincial adjacency". Distance between capitals is represented by the distance (in kilometers) between two provinces' capitals via national railway. The data on distance between capitals are calculated by the author based on the data released by the Ministry of Railways of the People's Republic of China.

In this paper, a comprehensive method is used to construct interprovincial ethnic linkages. Suppose that there are $k$ ethnic groups in both provinces $i$ and $j$. If the $i$ th and jth provinces' population shares for the $k$ th ethnic group are expressed by $x_{k}$ (it ranges between 0 and 1 ) and $y_{k}$ (it ranges between 0 and 1), respectively, the $k$ th ethnic group's linkage index between provinces $i$ and $j$ can be measured by the following formula:

$\mathrm{ETHNIC}_{i j k}=\min \left(x_{k}, y_{k}\right)$, where $x_{k} \in(0,1)$ and $y_{k} \in(0,1)$.

In Eq. (5), min (•) denotes the minimization of the variables within parentheses. The data on the population shares $\left(x_{k}\right.$ and $\left.y_{k}\right)$ are calculated by the author based on the data released by the Fifth and Sixth National Population Census of the People's Republic of China (conducted at 0:00 a.m. on November 1 of 2000 and 2010, respectively).

Since there are 56 ethnic groups in China, the overall ethnic linkage between provinces $i$ and $j$ can be measured by the following formula:

$$
\begin{aligned}
\text { ETHNIC } 56_{i j} & =\text { ETHNIC }_{i j_{1}}+\mathrm{ETHNIC}_{i j_{2}}+\ldots+\mathrm{ETHNIC}_{i j_{56}} \\
& =\sum_{k=1}^{56} \min \left(x_{k}, y_{k}\right)
\end{aligned}
$$

In Equation (6), min (•) denotes the minimization of the variables within parentheses. For all $k, x_{k} \in(0,1), y_{k} \in(0,1)$, and $\sum x_{k}=\sum y_{k}=1$. Consequently, ETHNIC56 $i j$ ranges between 0 and 1 . In the extreme cases, when ETHNIC56 $6_{i j}=1$, provinces $i$ and $j$ have a 
common ethnic structure (i.e., for all $k, x_{k}=y_{k}$ ); when ETHNIC56 $6_{i j}=0$, the two provinces do not have any ethnic linkage with each other (i.e., for all $k, x_{k}\left(\right.$ or $\left.y_{k}\right)=0$ ). In other words, greater values of ETHNIC56 $6_{i j}$ indicate greater degrees of ethnic linkages between the two provinces. This formula has been used in Guo $(2004 ; 2009$, p. 89) and Noland (2005). ${ }^{10}$

A brief statistical description of selected variables included in Eqs. (1), (2), and (3) is given in Table 2 (for 2000) and Table 3 (for 2010). The largest numbers of observations (i.e., interprovincial samples) are 465 for both 2000 and 2010. However, because the data on interprovincial trade are unavailable for the two provinces of Hainan and Tibet (including 59 province pairs) from 2000 as well as for 13 province pairs (i.e., Beijing-Hainan, Guizhou-Tibet, Hainan-Heilongjiang, Hainan-Jilin, Hainan-Liaoning, Hainan-Ningxia, Hainan-Shanghai, Hainan-Tianjin, Hainan-Tibet, Hainan-Xinjiang, Jilin-Tibet, Ningxia-Tibet, and Tibet-Yunnan) from 2010, the total numbers of observations that can be actually used for our regressions are reduced to 406 (i.e., $465-59=406$ ) for 2000 and 452 (i.e., $465-13=452$ ) for 2010 accordingly.

\section{Results and discussion}

The gravity models constructed in "Methods" section can be tested by using the data described in "The data" section. We first run Eq. (1) by using both the data of 2000 and 2010 (the estimated results are shown in the second and third columns of Table 4, respectively) and the pooled data (the estimated results are shown in Table 5 in which the year-fixed effects on trade are also included in regression shown in the third column).

Early comparative studies, using the international panel data of China and East Asia, show that geographical influence on international trade was reduced from the 1980s to 1990s (Guo 2007; 2013, p. 210). One of the major driving forces contributing to this tendency might be technological advance in transportation and communications. Intuitively, wide application of E-commerce and the declining of distance-related transactions costs have increasingly contributed to the growth of international trade. However, in this paper, the negative effect of "distance" on interprovincial trade is found to rise from 2000 to 2010. Obviously, this does not reflect China's improvement of transport infrastructures; neither does it conform to the general pattern of international trade. The main cause of China's interprovincial trade barriers may be the market-segmenting behavior that the Chinese provinces carry on in order to maintain social stability and maximize fiscal incomes (Poncet 2005). Undoubtedly, our finding shows a sign of China's spatial economic disintegration during the first decade of the twenty-first century.

The estimated coefficients on "ADJACENT", which are statistically significant, slightly increase from 2000 to 2010 (see Table 4). However, the year-fixed effect derived from the regression based on the pooled data (see the third column of Table 5) does not show any statistical significance for this kind of increase.

The estimated coefficients on "ETHNIC56" are statistically significant for 2000 and 2010. However, they are negative, suggesting that the interprovincial links of 56 ethnic groups as a whole have only but impeded China's interprovincial economic activities. Obviously, this provides no evidence that supports the widely 
Table 2 Descriptive statistics for the data on selected variables, 2000

\begin{tabular}{|c|c|c|c|c|c|}
\hline Variable & $N$ & Minimum & Maximum & Mean & SD \\
\hline $\ln \left(\operatorname{TRADE}_{i j}\right)$ & 406 & 2.99573 & 11.59910 & 6.84499 & 1.36932 \\
\hline $\ln \left(G D P_{j} G D P_{j}\right)$ & 465 & 5.73532 & 13.62832 & 10.70744 & 1.43231 \\
\hline $\ln \left(\mathrm{GDPPC}_{i} \mathrm{GDPPC}_{j}\right)$ & 465 & 16.19674 & 20.00507 & 17.70224 & 0.69716 \\
\hline $\ln \left(D_{I S T A N C E}\right)$ & 465 & 4.91998 & 8.75037 & 7.47203 & 0.64053 \\
\hline ETHNIC56 $i j$ & 465 & 0.06160 & 0.99930 & 0.75563 & 0.24827 \\
\hline$k=1$. Bai & 465 & 0.00001 & 0.00532 & 0.00004 & 0.00028 \\
\hline$k=2$. Blang & 465 & 0.00000 & 0.00001 & 0.00000 & 0.00000 \\
\hline$k=3$. Buyi & 465 & 0.00001 & 0.00129 & 0.00005 & 0.00008 \\
\hline$k=4$. Dai & 465 & 0.00000 & 0.00008 & 0.00000 & 0.00001 \\
\hline$k=5$. Daur & 465 & 0.00000 & 0.00120 & 0.00001 & 0.00006 \\
\hline$k=6$. Dong & 465 & 0.00001 & 0.01331 & 0.00011 & 0.00077 \\
\hline$k=7$. Dongxiang & 465 & 0.00000 & 0.00303 & 0.00001 & 0.00015 \\
\hline k $=8$. Gelao & 465 & 0.00000 & 0.00009 & 0.00001 & 0.00001 \\
\hline$k=9 . \operatorname{Han}$ & 465 & 0.06061 & 0.99682 & 0.74690 & 0.25065 \\
\hline$k=10$. Hani & 465 & 0.00000 & 0.00003 & 0.00001 & 0.00001 \\
\hline$k=11$. Hui & 465 & 0.00025 & 0.15621 & 0.00371 & 0.00904 \\
\hline$k=12$. Jingpo & 465 & 0.00000 & 0.00001 & 0.00000 & 0.00000 \\
\hline$k=13$. Kazak & 465 & 0.00000 & 0.00012 & 0.00000 & 0.00001 \\
\hline$k=14$. Kirgiz & 465 & 0.00000 & 0.00004 & 0.00000 & 0.00000 \\
\hline$k=15$. Korean & 465 & 0.00002 & 0.01072 & 0.00013 & 0.00064 \\
\hline$k=16$. Lahu & 465 & 0.00000 & 0.00002 & 0.00000 & 0.00000 \\
\hline$k=17 . \mathrm{Li}$ & 465 & 0.00000 & 0.00159 & 0.00001 & 0.00007 \\
\hline$k=18$. Lisu & 465 & 0.00000 & 0.00023 & 0.00000 & 0.00001 \\
\hline$k=19$. Manchu & 465 & 0.00006 & 0.03705 & 0.00118 & 0.00443 \\
\hline$k=20$. Maonan & 465 & 0.00000 & 0.00089 & 0.00000 & 0.00004 \\
\hline$k=21$. Miao & 465 & 0.00004 & 0.03037 & 0.00069 & 0.00280 \\
\hline$k=22$. Mongol & 465 & 0.00008 & 0.01789 & 0.00064 & 0.00164 \\
\hline$k=23$. Mulao & 465 & 0.00000 & 0.00081 & 0.00000 & 0.00004 \\
\hline$k=24$. Naxi & 465 & 0.00000 & 0.00047 & 0.00000 & 0.00002 \\
\hline$k=25$. Qiang & 465 & 0.00000 & 0.00004 & 0.00000 & 0.00000 \\
\hline$k=26$. Salar & 465 & 0.00000 & 0.00047 & 0.00000 & 0.00003 \\
\hline$k=27$. She & 465 & 0.00000 & 0.00372 & 0.00004 & 0.00024 \\
\hline$k=28$. Shui & 465 & 0.00000 & 0.00035 & 0.00001 & 0.00003 \\
\hline$k=29$. Tibetan & 465 & 0.00002 & 0.22530 & 0.00074 & 0.01057 \\
\hline$k=30 . \mathrm{Tu}$ & 465 & 0.00000 & 0.00121 & 0.00002 & 0.00006 \\
\hline$k=31$. Tujia & 465 & 0.00003 & 0.04172 & 0.00066 & 0.00438 \\
\hline$k=32$. Uygur & 465 & 0.00002 & 0.00027 & 0.00004 & 0.00002 \\
\hline$k=33 . \mathrm{Va}$ & 465 & 0.00000 & 0.00005 & 0.00000 & 0.00000 \\
\hline$k=34$. Xibe & 465 & 0.00000 & 0.00187 & 0.00001 & 0.00009 \\
\hline$k=35$. Yao & 465 & 0.00000 & 0.01114 & 0.00009 & 0.00064 \\
\hline$k=36 . Y i$ & 465 & 0.00002 & 0.02577 & 0.00022 & 0.00196 \\
\hline$k=37$. Zhuang & 465 & 0.00005 & 0.02701 & 0.00025 & 0.00142 \\
\hline
\end{tabular}

Definitions of the variables shown in this table are given in the text $N$ number of observations, and SD standard deviation 
Table 3 Descriptive statistics for the data on selected variables, 2010

\begin{tabular}{|c|c|c|c|c|c|}
\hline Variable & $N$ & Minimum & Maximum & Mean & SD \\
\hline $\ln \left(\operatorname{TRADE}_{i j}\right)$ & 452 & 2.30259 & 12.62984 & 6.95446 & 1.76181 \\
\hline $\ln \left(G D P_{j} G D P_{j}\right)$ & 465 & 8.83243 & 16.76316 & 13.75672 & 1.38476 \\
\hline $\ln \left(\mathrm{GDPPC}_{i} \mathrm{GDPPC}_{j}\right)$ & 465 & 19.15152 & 22.40275 & 20.60043 & 0.62203 \\
\hline $\ln \left(D_{I S T A N C E}\right)$ & 465 & 4.91998 & 8.75037 & 7.47203 & 0.64053 \\
\hline ETHNIC56 $i j$ & 465 & 0.08280 & 0.99870 & 0.75979 & 0.24414 \\
\hline$k=1$. Bai & 465 & 0.00000 & 0.00526 & 0.00005 & 0.00027 \\
\hline$k=2$. Blang & 465 & 0.00000 & 0.00016 & 0.00000 & 0.00001 \\
\hline$k=3$. Buyi & 465 & 0.00001 & 0.00231 & 0.00007 & 0.00016 \\
\hline$k=4$. Dai & 465 & 0.00000 & 0.00011 & 0.00001 & 0.00002 \\
\hline$k=5$. Daur & 465 & 0.00000 & 0.00105 & 0.00001 & 0.00005 \\
\hline$k=6$. Dong & 465 & 0.00001 & 0.01301 & 0.00013 & 0.00076 \\
\hline$k=7$. Dongxiang & 465 & 0.00000 & 0.00282 & 0.00002 & 0.00015 \\
\hline k $=8$. Gelao & 465 & 0.00000 & 0.00033 & 0.00001 & 0.00003 \\
\hline$k=9 . \operatorname{Han}$ & 465 & 0.08176 & 0.99660 & 0.75070 & 0.24660 \\
\hline$k=10$. Hani & 465 & 0.00000 & 0.00014 & 0.00001 & 0.00001 \\
\hline$k=11$. Hui & 465 & 0.00020 & 0.14827 & 0.00356 & 0.00865 \\
\hline$k=12$. Jingpo & 465 & 0.00000 & 0.00002 & 0.00000 & 0.00000 \\
\hline$k=13$. Kazak & 465 & 0.00000 & 0.00071 & 0.00002 & 0.00004 \\
\hline$k=14$. Kirgiz & 465 & 0.00000 & 0.00089 & 0.00000 & 0.00004 \\
\hline$k=15$. Korean & 465 & 0.00001 & 0.00856 & 0.00013 & 0.00058 \\
\hline$k=16$. Lahu & 465 & 0.00000 & 0.00003 & 0.00000 & 0.00000 \\
\hline$k=17 . \mathrm{Li}$ & 465 & 0.00001 & 0.00396 & 0.00003 & 0.00018 \\
\hline$k=18$. Lisu & 465 & 0.00000 & 0.00026 & 0.00001 & 0.00001 \\
\hline$k=19$. Manchu & 465 & 0.00011 & 0.03156 & 0.00111 & 0.00378 \\
\hline$k=20$. Maonan & 465 & 0.00000 & 0.00080 & 0.00000 & 0.00004 \\
\hline$k=21$. Miao & 465 & 0.00005 & 0.03136 & 0.00088 & 0.00296 \\
\hline$k=22$. Mongol & 465 & 0.00005 & 0.01774 & 0.00056 & 0.00157 \\
\hline$k=23$. Mulao & 465 & 0.00000 & 0.00073 & 0.00001 & 0.00003 \\
\hline$k=24$. Naxi & 465 & 0.00000 & 0.00038 & 0.00000 & 0.00002 \\
\hline$k=25$. Qiang & 465 & 0.00000 & 0.00005 & 0.00001 & 0.00001 \\
\hline$k=26$. Salar & 465 & 0.00000 & 0.00053 & 0.00001 & 0.00003 \\
\hline$k=27$. She & 465 & 0.00000 & 0.00306 & 0.00004 & 0.00021 \\
\hline$k=28$. Shui & 465 & 0.00000 & 0.00029 & 0.00001 & 0.00003 \\
\hline$k=29$. Tibetan & 465 & 0.00002 & 0.24438 & 0.00080 & 0.01149 \\
\hline$k=30 . \mathrm{Tu}$ & 465 & 0.00000 & 0.00120 & 0.00003 & 0.00007 \\
\hline$k=31$. Tujia & 465 & 0.00006 & 0.04210 & 0.00079 & 0.00438 \\
\hline$k=32$. Uygur & 465 & 0.00001 & 0.00036 & 0.00004 & 0.00003 \\
\hline$k=33 . \mathrm{Va}$ & 465 & 0.00000 & 0.00006 & 0.00001 & 0.00001 \\
\hline$k=34$. Xibe & 465 & 0.00000 & 0.00158 & 0.00001 & 0.00008 \\
\hline$k=35$. Yao & 465 & 0.00001 & 0.01086 & 0.00011 & 0.00064 \\
\hline$k=36 . Y i$ & 465 & 0.00002 & 0.03288 & 0.00027 & 0.00220 \\
\hline$k=37$. Zhuang & 465 & 0.00005 & 0.02644 & 0.00031 & 0.00141 \\
\hline
\end{tabular}

Definitions of the variables shown in this table are given in the text $N$ number of observations, and SD standard deviation 
Table 4 Basic regressions-56 ethnic groups as a single variable, 2000 and 2010

\begin{tabular}{lll}
\hline Explanatory variable & Coefficient in 2000 & Coefficient in 2010 \\
\hline Constant & $14.461^{\mathrm{a}}(1.462)$ & $29.057^{\mathrm{a}}(2.447)$ \\
$\operatorname{In}\left(\mathrm{GDP}_{j} \mathrm{GDP}_{j}\right)$ & $0.647^{\mathrm{a}}(0.046)$ & $0.759^{\mathrm{a}}(0.063)$ \\
$\operatorname{In}\left(\mathrm{GDPPC}_{i} \mathrm{GDPPC}_{j}\right)$ & $-0.253^{\mathrm{a}}(0.072)$ & $-1.041^{\mathrm{a}}(0.108)$ \\
$\operatorname{In}\left(\mathrm{DISTANCE}_{i j}\right)$ & $-1.212^{\mathrm{a}}(0.097)$ & $-1.377^{\mathrm{a}}(0.127)$ \\
ADJACENT $_{i j}$ & $0.504^{\mathrm{a}}(0.149)$ & $0.579^{\mathrm{a}}(0.196)$ \\
ETHNIC56 $_{i j}$ & $-1.560^{\mathrm{a}}(0.324)$ & $-1.393^{\mathrm{a}}(0.367)$ \\
PD & $-0.350^{\mathrm{a}}(0.099)$ & $-0.521^{\mathrm{a}}(0.134)$ \\
Coefficient of correlation $\left(R^{2}\right)$ & 0.644 & 0.586 \\
Standard error of regression & 0.823 & 1.141 \\
F statistic & 120.556 & 104.786 \\
Sig. of regression & 0.000 & 0.000 \\
Number of observations & 405 & 451 \\
\hline
\end{tabular}

Dependent variable is the natural log of interprovincial trade. Figures within parentheses are standard errors. The variance inflation factors (VIFs) are all less than 2.5, which are not reported in the table

"a" Denotes statistically significant at greater than the $1 \%$ level

recognizable view that ethnic linkage index tends to encourage trade between provinces that are multiethnically linked. In fact, since the partial correlation between the natural $\log$ of TRADE and the ETHNIC56 scores yields an inverted-U shape curve for 2010 (see Fig. 1), the above estimated coefficients on ETHNIC56 may be misleading (at least for 2010).

Let us now run Eq. (2) constructed in the "Methods" section. In China's Fifth National Population Census conducted in November 2000, only permanent populations were counted (whereas in 2010, those who had stayed at their current residences for

Table 5 Regressions based on pooled data—56 ethnic groups as a single variable

\begin{tabular}{|c|c|c|}
\hline Explanatory variable & Coefficient (excl. year-fixed effects) & Coefficient (incl. year-fixed effects) \\
\hline Constant & $30.733^{\mathrm{a}}(1.840)$ & $30.764^{\mathrm{a}}(1.839)$ \\
\hline $\ln \left(G D P_{j} G D P_{j}\right)$ & $0.865^{\mathrm{a}}(0.047)$ & $0.862^{\mathrm{a}}(0.047)$ \\
\hline $\ln \left(G D P P C_{j} G D P P C_{j}\right)$ & $-1.131^{\mathrm{a}}(0.081)$ & $-1.129^{\mathrm{a}}(0.081)$ \\
\hline $\ln \left(\right.$ DISTANCE $\left._{i j}\right)$ & $-1.486^{\mathrm{a}}(0.095)$ & $-1.450^{\mathrm{a}}(0.097)$ \\
\hline In(DISTANCE $i$ ) in 2010 & - & $-0.064^{\mathrm{b}}(0.031)$ \\
\hline ADJACENT $_{i j}$ & $0.429^{\mathrm{a}}(0.148)$ & $0.466^{a}(0.190)$ \\
\hline ADJACENT $_{i j}$ in 2010 & - & $-0.065(0.236)$ \\
\hline ETHNIC56 $6_{i j}$ & $-1.694^{\mathrm{a}}(0.274)$ & $-1.939^{\mathrm{a}}(0.313)$ \\
\hline ETHNIC56 $6_{i j}$ in 2010 & - & $0.487^{\complement}(0.298)$ \\
\hline PD & $-0.587^{\mathrm{a}}(0.102)$ & $-0.587^{\mathrm{a}}(0.101)$ \\
\hline Coefficient of correlation $\left(\mathrm{R}^{2}\right)$ & 0.598 & 0.600 \\
\hline Standard error of regression & 1.229 & 1.228 \\
\hline F statistic & 225.620 & 151.267 \\
\hline Sig. of regression & 0.000 & 0.000 \\
\hline Number of observations & 856 & 856 \\
\hline
\end{tabular}

Dependent variable is the natural log of interprovincial trade. The variance inflation factors (VIFs) are all less than 2.5 , which are not reported in the table. Figures within parentheses are standard errors

"an", "b", and "c"Denote statistically significant at greater than the 1, 5, and $10 \%$ levels, respectively 

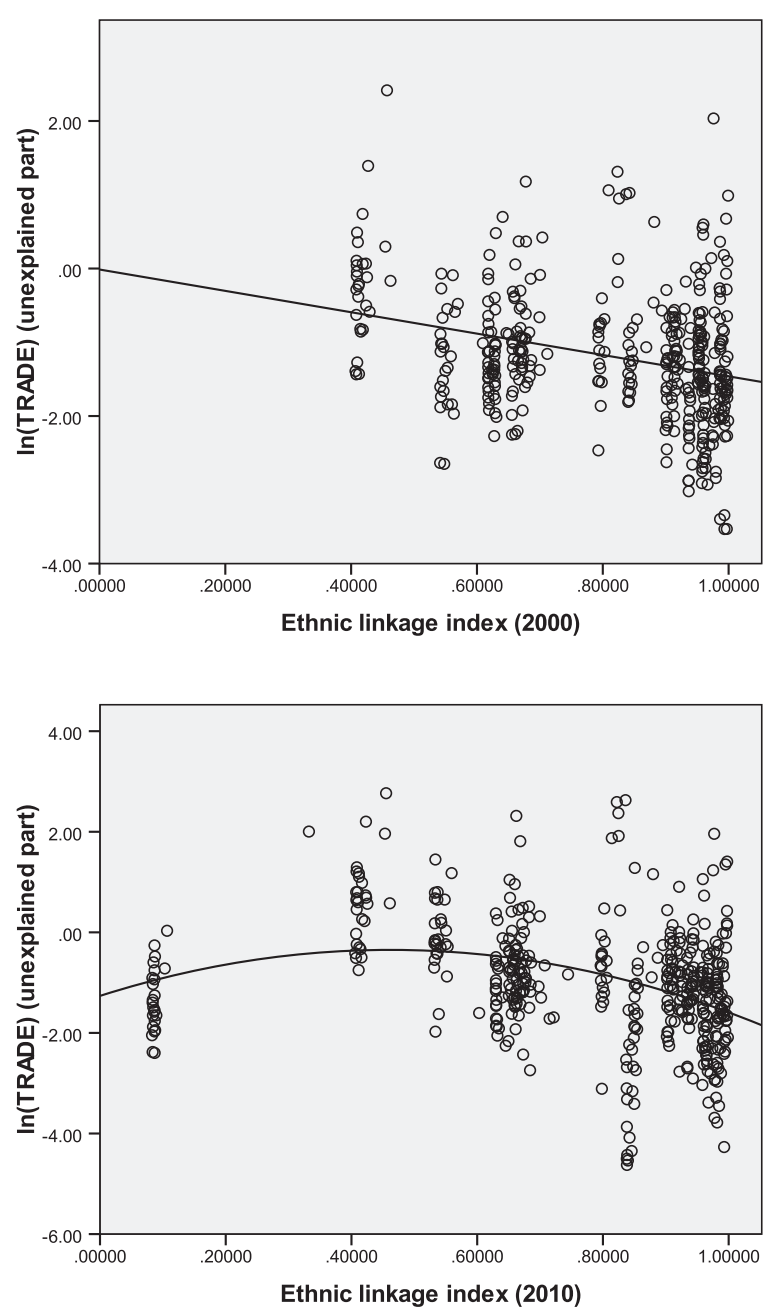

Fig. 1 Partial correlations between trade and ethnic linkage, 2000 and 2010. Sources: Table 6 for the estimated coefficients (2010) and Appendix for ethnic population

6 months or longer were also counted). This could affect the final estimated coefficients in 2000 (remember that the "floating" populations may sometimes play more important roles in interprovincial marketing and trade than in permanent residents). To this end, we will not use the pooled data of 2000 and 2010; instead, we will only run regressions based on the data of 2000 and 2010, respectively. The estimated results shown in Table 6 are derived by excluding the variables whose variance inflation factors (VIFs) exceed 10 (a value that is often regarded as indicating multicollinearity). These results, compared with those shown in Tables 4 and 5, can help us to better explain the diverse ethnic influences on interprovincial trade:

- As for 2000, seven ethnic groups (Jingpo, Gelao, Manchu, Hui, Dongxiang, Daur, and Maonan) have positive effects; four ethnic groups (Han, Li, Hani, and Buyi) have negative effects on interprovincial trade; and 26 ethnic variables (Bai, Blang, Dai, Dong, Kazak, Kirgiz, Korean, Lahu, Lisu, Miao, Mongol, Mulao, Naxi, Qiang, 
Table 6 The estimated coefficients on the ethnic variables defined in Eq. (2)

\begin{tabular}{|c|c|c|c|c|}
\hline \multirow[t]{2}{*}{ Explanatory variable } & \multicolumn{2}{|l|}{2000} & \multicolumn{2}{|l|}{2010} \\
\hline & Coefficient & Standard error & Coefficient & Standard error \\
\hline 1. Bai & & & -192.637 & 341.756 \\
\hline 2. Blang & $-11,4466.708$ & $83,123.810$ & $-36,909.300^{b}$ & $17,153.46$ \\
\hline 3. Buyi & $-1989.870^{c}$ & 1044.715 & 767.807 & 753.124 \\
\hline 4. Dai & $-17,883.500$ & $14,948.590$ & $-16,349.312^{a}$ & 5046.068 \\
\hline 5. Daur & $1432.134^{b}$ & 656.009 & $2586.816^{a}$ & 951.629 \\
\hline 6. Dong & 48.212 & 69.223 & 68.102 & 91.598 \\
\hline 7. Dongxiang & $1284.739^{\mathrm{a}}$ & 488.076 & $1515.314^{\mathrm{a}}$ & 433.379 \\
\hline 8. Gelao & $27,798.940^{\mathrm{a}}$ & 9578.905 & -4593.947 & 4339.398 \\
\hline 9. Han & $-1.350^{\mathrm{a}}$ & 0.319 & $-1.421^{\mathrm{a}}$ & 0.359 \\
\hline 10. Hani & $-24,297.300^{b}$ & $11,902.110$ & -1843.340 & 8839.561 \\
\hline 11. Hui & $10.359^{\mathrm{b}}$ & 4.765 & $13.374^{b}$ & 6.508 \\
\hline 12. Jingpo & $245,643.800^{\mathrm{a}}$ & 75461.210 & $60,181.957^{\mathrm{a}}$ & 33170.5 \\
\hline 13. Kazak & -9719.600 & $11,494.670$ & $-10010.414^{a}$ & 3264.211 \\
\hline 14. Kirgiz & $-17,486.600$ & $19,645.340$ & $5896.574^{b}$ & 2606.726 \\
\hline 15. Korean & -44.290 & 70.080 & -91.085 & 103.646 \\
\hline 16. Lahu & 1913.425 & $34,644.910$ & $69,627.249^{a}$ & $27,110.080$ \\
\hline 17. $\mathrm{Li}$ & $-25132.900^{\mathrm{a}}$ & 9002.619 & -249.689 & 262.76 \\
\hline 18. Lisu & 8126.747 & 6308.788 & 7117.415 & 7282.878 \\
\hline 19. Manchu & $52.555^{\mathrm{a}}$ & 11.183 & $48.142^{\mathrm{a}}$ & 17.541 \\
\hline 20. Maonan & $2042.121^{c}$ & 1088.550 & $4115.362^{b}$ & 1693.773 \\
\hline 21. Miao & 2.001 & 23.957 & -7.926 & 34.356 \\
\hline 22. Mongol & 35.200 & 26.217 & $132.086^{\mathrm{a}}$ & 36.313 \\
\hline \multicolumn{5}{|l|}{ 23. Mulao } \\
\hline 24. Naxi & & & -2385.250 & 8354.333 \\
\hline 25. Qiang & 4665.429 & $16,645.120$ & $35,288.611^{\mathrm{a}}$ & $12,540.510$ \\
\hline \multicolumn{5}{|l|}{ 26. Salar } \\
\hline 27. She & 58.482 & 152.286 & $452.580^{c}$ & 245.120 \\
\hline 28. Shui & & & -4178.755 & 2932.771 \\
\hline 29. Tibetan & 45.738 & 35.168 & $9.441^{b}$ & 4.825 \\
\hline 30. Tu & -415.235 & 1047.778 & $3469.553^{c}$ & 2133.557 \\
\hline 30. Tujia & -8.852 & 11.024 & -8.700 & 14.283 \\
\hline 31. Uygur & 1081.944 & 2407.569 & 1386.841 & 1977.202 \\
\hline 32. Va & $12,915.170$ & $13,274.480$ & $-42,682.902^{a}$ & $11,427.990$ \\
\hline 33. Xibe & -65.376 & 411.421 & -194.667 & 660.486 \\
\hline 34. Yao & 21.566 & 75.760 & 80.423 & 101.235 \\
\hline 35. Yi & 9.209 & 36.782 & -4.697 & 40.519 \\
\hline 36. Zhuang & 45.252 & 33.230 & $98.107^{b}$ & 42.746 \\
\hline Coefficient of correlation $\left(R^{2}\right)$ & 0.745 & & 0.645 & \\
\hline Standard error of regression & 0.725 & & 1.095 & \\
\hline F statistic & 29.877 & & 20.337 & \\
\hline Sig. of regression & 0.000 & & 0.000 & \\
\hline Number of observations & 405 & & 451 & \\
\hline
\end{tabular}

Only the coefficients on ethnic variables are included in this table. The ethnic variables whose variance inflation factors (VIFs) are larger than 10 are omitted from regressions

"an" " "b"' and "'Denote statistically significant at greater than the 1, 5, and $10 \%$ levels, respectively 
Salar, She, Shui, Tibetan, Tu, Tujia, Uygur, Va, Xibe, Yao, Yi, and Zhuang) are not found to have any significant influences on trade.

- As for 2010, 14 ethnic groups (Lahu, Qiang, Jingpo, Tu, Mongol, Manchu, Hui, Zhuang, Dongxiang, Daur, Kirgiz, She, Maonan, and Tibetan) have positive effects on interprovincial trade; five ethnic groups (Han, Va, Kazak, Dai, and Blang) have negative effects; and 18 ethnic variables (Bai, Buyi, Dong, Gelao, Hani, Korean, Li, Lisu, Miao, Mulao, Naxi, Salar, Shui, Tujia, Uygur, Xibe, Yao, and Yi) are not found to have any significant influences on trade.

Remember that there is a negative relationship between China's interprovincial ethnic links and trade, which can be witnessed by the negative coefficients on ETHNIC56 in Tables 4 and 5 . Then why there are fewer ethnic groups with negative influences on interprovincial trade than those with positive influences? This may plausibly stem from the very fact that the Han majority whose estimated coefficients are negative for both 2000 and 2010 (see Table 6) has a much larger weight than any other ethnic minorities.

Using the estimated coefficients reported in Table 6, one may calculate each ethnic group's contribution to interprovincial trade (the results are reported in Table 7). Here, take the Hui ethnic group as an example. As shown in Table 3, the minimum, maximum, and mean values of interprovincial ethnic links-represented by $\mathrm{ETHNIC}_{i j 11}$ in Eq. (2)-are 0.00020 (i.e., the one for Jiangxi and Zhejiang), 0.14827 (i.e., the one for Ningxia and Qinghai), and 0.00356, respectively, in 2010. Given that the estimated coefficient on $\mathrm{ETHNIC}_{i j 11}$ is 13.374 (shown in Table 6), the Hui's contribution to interprovincial trade in 2010 ranges from 0.268 (that is, $\exp (0.00020 \times 13.374) \times 100-100$ ) percent to 626.423 (that is, $\exp (0.14827 \times 13.374) \times 100-100)$ percent, with the mean value being 4.876 (that is, $\exp (0.00356 \times 13.374) \times 100-100)$ percent.

It must be noted that the estimated coefficients on some important ethnic minorities-such as Miao, Tibet, Uygur, Xibe, Yao, Yi and Zhuang-are statistically insignificant in either 2000 or 2010 (see Table 6). Technically, if an ethnic group is not found to exert any significant influences on China's interprovincial trade, it may have, subject to different economic conditions, both positive and negative effects on the trade of different groups of provinces. In order to test this kind of non-linear effects, let us run Eq. (3). Since, as mentioned earlier, the quality of 2000's ethnic data is less reliable than that of 2010's, we only test the regression by using 2010's data. Unfortunately, we cannot derive more encouraging results (the estimated coefficients are not reported here).

Nevertheless, we do find that some ethnic groups (such as the Hui, the Mancu, the Mongol, and the Zhuang) have some non-linear influences on interprovincial trade. Specifically, the above regression yields not only positive coefficients on these ethnic minorities (i.e., $\beta_{k}>0$ ) but also a negative coefficient (i.e., $\alpha_{4}<0$ ) on the interaction of ETHNIC56 and the income levels of trading partners (measured by the natural log of their per capita GDPs). However, since the threshold value-i.e., $\ln \left(\mathrm{GDPPC}_{i} \mathrm{GDPPC}_{j}\right)_{k}^{*}$ defined in Eq. (4) - is extremely large, the fundamental changes of these ethnic groups' positive effects on interprovincial trade will not occur in the near future.

\section{Conclusions}

During the past decades, along with the gradual reform in the decentralization of authority (that is, transferring economic management and decision making from the 
Table 7 Quantifying the ethnic groups' contributions to interprovincial trade (\%)

\begin{tabular}{|c|c|c|c|c|c|c|}
\hline \multirow[t]{2}{*}{ Ethnic group } & \multicolumn{3}{|l|}{2000} & \multicolumn{3}{|l|}{2010} \\
\hline & Minimum value & Maximum value & Mean value & Minimum value & Maximum value & Mean value \\
\hline \multicolumn{7}{|l|}{ 1. Bai } \\
\hline 2. Blang & & & & 0.000 & -99.734 & -2.643 \\
\hline 3. Buyi & -2.057 & -98.996 & -12.583 & & & \\
\hline 4. Dai & & & & -3.191 & -83.380 & -18.414 \\
\hline 5. Daur & 0.085 & 350.646 & 1.170 & 0.154 & 1417.056 & 2.123 \\
\hline \multicolumn{7}{|l|}{ 6. Dong } \\
\hline 7. Dongxiang & 0.047 & 3668.286 & 2.256 & 0.056 & 7127.996 & 2.666 \\
\hline 8. Gelao & 6.748 & $882,465.122$ & 51.102 & & & \\
\hline 9. Han & -10.450 & -73.957 & -63.703 & -10.968 & -75.736 & -65.587 \\
\hline 10. Hani & -6.241 & -96.533 & -22.619 & & & \\
\hline 11. Hui & 0.207 & 364.588 & 3.762 & 0.268 & 626.423 & 4.876 \\
\hline 12. Jingpo & 0.000 & 6032.297 & 53.249 & 0.000 & 174.133 & 11.025 \\
\hline 13. Kazak & & & & -4.219 & -99.922 & -22.057 \\
\hline 14. Kirgiz & & & & 0.035 & $19,224.296$ & 1.813 \\
\hline \multicolumn{7}{|l|}{ 15. Korean } \\
\hline 16. Lahu & & & & 2.019 & 737.508 & 28.358 \\
\hline 17. Li & -19.574 & -10.000 & -57.647 & & & \\
\hline \multicolumn{7}{|l|}{ 18. Lisu } \\
\hline 19. Manchu & 0.584 & 425.169 & 5.992 & 0.535 & 356.895 & 5.475 \\
\hline 20. Maonan & 0.027 & 412.995 & 0.697 & 0.054 & 2598.034 & 1.410 \\
\hline \multicolumn{7}{|l|}{ 21. Miao } \\
\hline 22. Mongol & & & & 0.626 & 941.393 & 7.657 \\
\hline \multicolumn{7}{|l|}{ 23. Mulao } \\
\hline \multicolumn{7}{|l|}{ 24. Naxi } \\
\hline 25. Qiang & & & & 3.181 & 425.512 & 28.270 \\
\hline \multicolumn{7}{|l|}{ 26. Salar } \\
\hline 27. She & & & & 0.096 & 298.641 & 1.680 \\
\hline \multicolumn{7}{|l|}{ 28. Shui } \\
\hline 29. Tibetan & & & & 0.015 & 904.629 & 0.759 \\
\hline 30. Tu & & & & 0.919 & 6409.243 & 10.314 \\
\hline \multicolumn{7}{|l|}{ 30. Tujia } \\
\hline \multicolumn{7}{|l|}{ 31. Uygur } \\
\hline 32. Va & & & & -6.882 & -91.864 & -37.559 \\
\hline \multicolumn{7}{|l|}{ 33. Xibe } \\
\hline \multicolumn{7}{|l|}{ 34. Yao } \\
\hline \multicolumn{7}{|l|}{ 35. Yi } \\
\hline 36. Zhuang & & & & 0.531 & 1238.236 & 3.037 \\
\hline
\end{tabular}

Figures in each row, which are calculated based on Tables 2 and 6, represent percentages by which provinces that are linked by the left-side ethnic group would increase (or decrease if the figures are negative) bilateral trade as opposed to those that are not linked by the same ethnic group. Blank denotes unavailability since either the ethnic variables are omitted from the regressions or the estimated coefficients are statistically insignificant in Table 6

central government to provincial and local governments), China's interprovincial relations have been transformed accordingly. Naturally, the examination of the driving forces to the causes and consequences of interprovincial economic (dis)integration in 
China is an important taskforce not only to the economists but also to the policymakers who have concerns about their internal spatial economic efficiencies.

It has been found that ethnic Chinese (mainly encompassing the Han ethnic Chinese) networks play an important role in international trade. Rauch and Trindade (2002), for example, find that ethnic Chinese networks have a quantitatively important impact on bilateral trade through the mechanisms of market information and matching and referral services, in addition to their effect through community enforcement of sanctions that deter opportunistic behavior. Their estimated results show that for trade between countries with ethnic Chinese population shares at the levels prevailing in Southeast Asia, the smallest estimated average increase in bilateral trade in differentiated products attributable to ethnic Chinese networks is nearly $60 \%{ }^{11}$

However, in this paper, we have not found any evidence that supports that the Han majority has played positive roles in China's interprovincial trade. Although it seems that more in-depth investigation is still needed, we believe that our small and negative coefficients on the Han (see Table 6) stem from the very fact that the Han majority accounts for more than $90 \%$ of China's total population (more than 1.3 billion). A large population per se also implies a great degree of diversity or dissimilarity of its members (Alesina and Spolaore 1997, p. 1029). As a result, a common standard cannot be fully realized among different provinces' Han people in China.

To develop this argument further, let us assume that China's domestic trade can be divided into interprovincial and intra-provincial trade, on the one hand, and interethnic and intra-ethnic trade, on the other hand. Obviously, according to the cost of transactions, intra-provincial trade is always preferable to interprovincial trade and intra-ethnic trade is preferable to interethnic trade. Therefore, ceteris paribus, the intra-provincial and intra-ethnic trade is always more profitable than the interprovincial and interethnic trade. If the population of an ethnic group is very small, then the intra-provincial and intra-ethnic trade is not able meet the demand of economic growth. As a result, the interprovincial and intra-ethnic and intra-provincial and interethnic trade may still be needed. In this case, the interprovincial and intra-ethnic trade is preferable to the intra-provincial and interethnic trade if the interprovincial transactions cost is lower than interethnic transactions cost, and vice versa. Figure 2, in which smaller ethnic groups have greater (in both positive and negative directions) effects on interprovincial trade, has provided evidence that small ethnic groups are always more important in promoting interprovincial trade than large ethnic groups.

We need to clarify the inherent forces and narratives behind the differing influences of all the ethnic minorities on China's spatial economic (dis)integration. For example, the Han-Uyghur unrest in and outside Xinjiang would have been responsible for the Uyghurs' insignificant effects on interprovincial trade; and Tibetans' positive influences on interprovincial trade in 2010 has benefited from the Qinghai-Tibet railway which went into operation in 2006. With the operation of the Qinghai-Tibet railway, the costs of transportation of both passengers and goods should be greatly reduced, allowing for an increase in volume-the costs per ton-kilometer will be reduced from 0.38 yuan to 0.12 yuan (Cnradio, 10 November 2006). As a result, more commodities will be carried to and from Tibet by the 


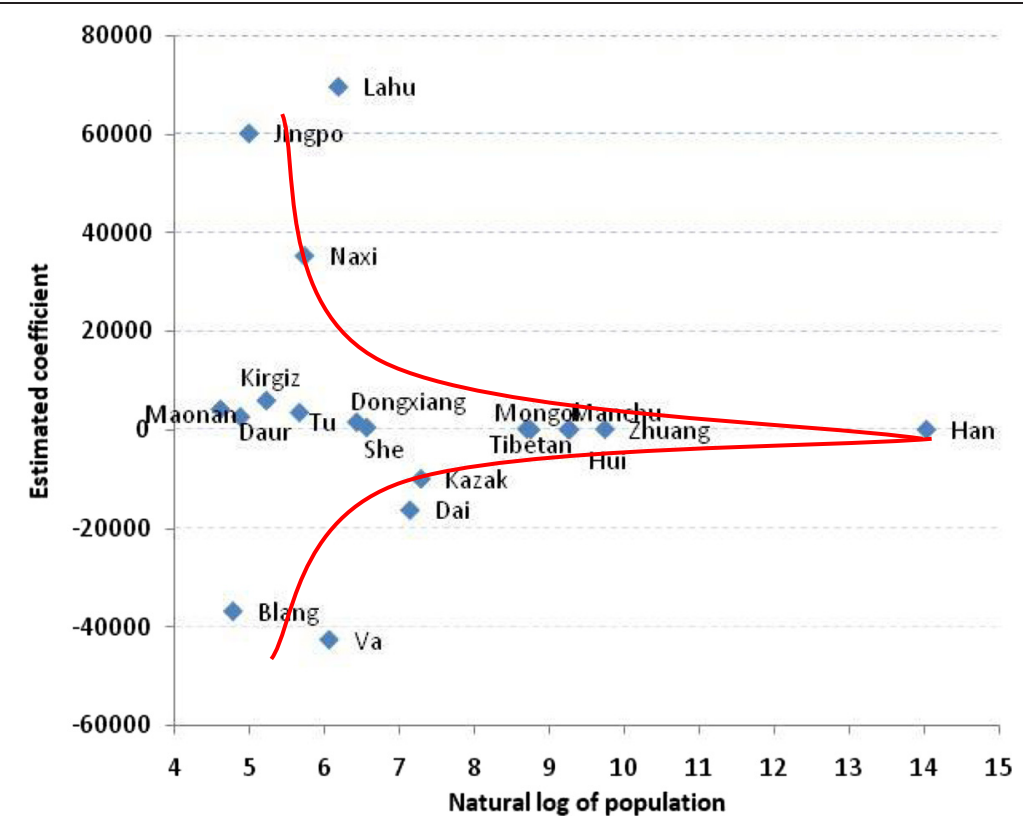

Fig. 2 Ethnic influence on interprovincial trade decreases with the size of ethnic population

railway. However, it seems that I am not able to clarify all the influences of each and all of China's 56 ethnic groups in a single paper.

Since China adopted different approaches when conducting the population census in 2000 and 2010, our ethnic data may not be comparable from 2000 to 2010. Therefore, cares should be taken when the changes of ethnic influences on interprovincial trade from 2000 to 2010 are to be clarified. But our estimated coefficients for 2010 seem to be more reliable than those for 2000 (shown in Table 6). If the 2010's results shown in Table 7 are correct, we may conclude that 14 ethnic groups (Lahu, Qiang, Jingpo, Tu, Mongol, Manchu, Hui, Zhuang, Dongxiang, Daur, Kirgiz, She, Maonan, and Tibetan) tend to contribute to China's interprovincial trade, that five ethnic groups (Han, Va, Kazak, Dai, and Blang) tend to retard China's interprovincial trade. These findings will be useful for policy makers to reappraise which of China's ethnic groups are playing the most (least) important roles in, and to introduce the optimal informal institutions into, the promotion of interprovincial economic cooperation in China.

It must be noted that interprovincial trade may also foster the interprovincial migration of ethnic groups in China, raising an issue of potential endogeneity in the analysis of ethnic influences on interprovincial trade in this paper. However, since our ethnic data only include permanent populations and that most, if not all, seasonable, shortstay migrants have only been officially defined as the "floating populations" (liudong renkou), this kind of potential endogeneity problem does not render the estimated results biased and inconsistent.

In order to overcome the problems with multicollinearity, we have omitted a number of ethnic groups from our regressions. The general rule of thumb is that variance inflation factor (endogeneity) exceeding 4 warrant further investigation, while those exceeding 10 are signs of serious multicollinearity requiring correction (Simon 2004). In weaker models, especially in those that are not supported by 
large sets of data, VIF above 2.5 may also merit further investigation (Berry and Feldman 1985, p. 49; Arceneaux and Huber 2007). In this paper, we have re-run all the regressions in Table 6 by omitting the explanatory variables with VIF exceeding 4 (the estimated results are not reported here). But we have found that the estimated results are quite stable after the variables with the VIF exceeding 10 are omitted from the regressions. Thus, even though the variables with VIF exceeding 4 are included, the estimated coefficients reported in this paper are not affected by multicollinearity.

\section{Endnotes}

${ }^{1}$ Calculated by author based on the data released by the World Trade Organization (Available at http://www.wto.org/english/thewto_e/countries_e/china_e.htm. Accessed 2013-5-20).

${ }^{2}$ Data sources: Rumbaugh and Blancher (2004) and WTO (2011).

${ }^{3}$ Note that Beijing and Shanghai's reductions of domestic trade from 2000 to 2010 are mainly due to their removals of large industrial, pollution-making plants during the above period.

${ }^{4}$ For a more detailed analysis of the distance puzzle, see Head and Disdier (2008).

${ }^{5}$ These trade barriers take a number of forms including legal and institutional differences (Anderson and Marcouiller 2002; Linders et al. 2005; Combes et al. 2005; and Guiso et al. 2006), ethnic/linguistic fractionalization (Rauch 2001; Rauch and Trindade 2002; Melitz 2008; and Felbermayr et al. 2010), and linguistic and religious dissimilarities (Guo 2004; 2007).

${ }^{6}$ The earliest application of the gravity model can be traced back to the 1940s (see, e.g., Zipf 1946; Stewart 1948). More recent summaries can be found in Baldwin and Taglioni (2006) and Head and Mayer (2013).

${ }^{7}$ Since GDPPC equals GDP/POP (where POP is population), Eq. (1) can be written as $\ln \left(\right.$ TRADE $\left._{i j}\right)=\alpha_{0}+\left(\alpha_{1}+\alpha_{4}\right) \ln \left(\right.$ GDP $_{i}$ GDP $\left._{j}\right)+\alpha_{2} \operatorname{lnDISTANCE}{ }_{i j}+\alpha_{3}$ ADJACENT $_{i j^{-}}$ $\alpha_{4} \ln \left(\mathrm{POP}_{i} \mathrm{POP}_{j}\right)+\alpha_{5} \mathrm{PD}+\beta \mathrm{ETHNIC}_{i j}$. However, we will not use this equation since the inclusion of GDP and POP — unlike that of GDP and GDPPC — can easily result in multicollinearity problems.

${ }^{8} \mathrm{~A}$ direct measure of transport costs (instead of distance) has been suggested as a proxy for trade costs, especially for within-country studies (Combes et al. 2005). However, since we only consider the trade via national railways in our research and that the per-kilometer costs of transportation via national railways are almost fixed throughout China, these two measures are not different from each other.

${ }^{9}$ They are compiled by China Association of Communications and Transportation and the National Development and Reform Commission of the PRC and published by China Communications Yearbook Press in 2001 and 2011, respectively.

${ }^{10}$ Several other methods can also be used. Boisso and Ferrantino (1997), for example, use $\sum x_{k} y_{k}$ as the construct of similarity index. However, Eq. (6) can prevent the index of interprovincial ethnic linkages from further reduction when the values of $x_{k}$ and $y_{k}$ are small.

${ }^{11}$ More recently, there is an empirical work in which the Chinese network is found to lead to a modest amount of trade creation of only about $15 \%$ (Felbermayr et al. 2010). 


\section{Appendix}

Table 8 Names and demographic distributions of China's 56 ethnic groups

\begin{tabular}{|c|c|c|}
\hline Name & Population (thousand persons) & Five major host provinces \\
\hline Achang* & 39.56 & Yunnan, Guangdong, Henan, Shandong, Jiangsu \\
\hline Bai & 1933.51 & Yunnan, Guizhou, Hunan, Guangdong, Zhejiang \\
\hline Baonan* & 20.07 & Gansu, Qinghai, Xinjiang, Inner Mongolia, Yunnan \\
\hline Blang & 119.64 & Yunnan, Guangdong, Shandong, Zhejiang, Chongqing \\
\hline Buyi & 2870.03 & Guizhou, Zhejiang, Guangdong, Yunnan, Fujian \\
\hline Dai & 1261.31 & Yunnan, Sichuan, Guangdong, Zhejiang, Shandong \\
\hline Daur & 131.99 & Inner Mongolia, Heilongjiang, Xinjiang, Beijing, Liaoning \\
\hline Deang* & 20.56 & Yunnan, Guangdong, Shandong, Zhejiang, Sichuan \\
\hline Derung* & 6.93 & Yunnan, Guizhou, Henan, Guangdong, Sichuan \\
\hline Dong & 2879.97 & Guizhou, Hunan, Guangxi, Zhejiang, Guangdong \\
\hline Dongxiang & 621.50 & Gansu, Xinjiang, Qinghai, Ningxia, Guizhou \\
\hline Ewenki* & 30.88 & Inner Mongolia, Heilongjiang, Liaoning, Beijing, Shandong \\
\hline Gaoshan* & 4.01 & Henan, Fujian, Guangxi, Liaoning, Hebei \\
\hline Gelao & 550.75 & Guizhou, Zhejiang, Guangdong, Guangxi, Yunnan \\
\hline Han & $1,220,844.52$ & Guangdong, Shandong, Henan, Jiangsu, Sichuan \\
\hline Hani & 1660.93 & Yunnan, Guangdong, Zhejiang, Shanghai, Shandong \\
\hline Hezhe* & 5.35 & Heilongjiang, Guangdong, Jilin, Beijing, Liaoning \\
\hline Hui & $10,586.09$ & Ningxia, Gansu, Xinjiang, Henan, Qinghai \\
\hline Jing* & 28.20 & Guangxi, Guizhou, Yunnan, Guangdong, Jiangxi \\
\hline Jingpo & 147.83 & Yunnan, Guangdong, Shandong, Guizhou, Jilin \\
\hline $\mathrm{Jino}^{*}$ & 23.14 & Yunnan, Sichuan, Chongqing, Guangdong, Jiangsu \\
\hline Kazak & 1462.59 & Xinjiang, Henan, Guangdong, Gansu, Hunan \\
\hline Kirgiz & 186.71 & Xinjiang, Tibet, Heilongjiang, Guangdong, Zhejiang \\
\hline Korean & 1830.93 & Jilin, Heilongjiang, Liaoning, Shandong, Beijing \\
\hline Lahu & 485.97 & Yunnan, Shandong, Zhejiang, Guangdong, Jiangsu \\
\hline Lhoba* & 3.68 & Tibet, Guizhou, Fujian, Beijing, Liaoning \\
\hline $\mathrm{Li}$ & 1463.06 & Hainan, Guizhou, Guangdong, Zhejiang, Guangxi \\
\hline Lisu & 702.84 & Yunnan, Sichuan, Hebei, Shandong, Guangdong \\
\hline Manchu & $10,387.96$ & Liaoning, Hebei, Jilin, Heilongjiang, Inner Mongolia \\
\hline Maonan & 101.19 & Guangxi, Guizhou, Guangdong, Zhejiang, Fujian \\
\hline Miao & 9426.01 & Guizhou, Hunan, Yunnan, Chongqing, Guangxi \\
\hline Monba* & 10.56 & Tibet, Jiangsu, Gansu, Jiangxi, Guangxi \\
\hline Mongol & 5981.84 & Inner Mongolia, Liaoning, Hebei, Xinjiang, Jilin \\
\hline Mulam & 216.26 & Guangxi, Guizhou, Guangdong, Zhejiang, Hunan \\
\hline Naxi & 326.30 & Yunnan, Sichuan, Tibet, Zhejiang, Beijing \\
\hline $\mathrm{Nu}^{*}$ & 37.52 & Yunnan, Hainan, Guangdong, Tibet, Shandong \\
\hline Oroqen* & 8.66 & Heilongjiang, Inner Mongolia, Liaoning, Beijing, Hebei \\
\hline Pumi* & 42.86 & Yunnan, Sichuan, Guangdong, Shandong, Chongqing \\
\hline Qiang & 309.58 & Sichuan, Guangdong, Guizhou, Zhejiang, Jiangsu \\
\hline Russian* & 15.39 & Xinjiang, Inner Mongolia, Beijing, Heilongjiang, Shanghai \\
\hline Salar & 130.61 & Qinghai, Gansu, Xinjiang, Shanghai, Guangdong \\
\hline She & 708.65 & Fujian, Zhejiang, Jiangxi, Guizhou, Guangdong \\
\hline Shui & 411.85 & Guizhou, Guangxi, Jiangsu, Zhejiang, Yunnan \\
\hline
\end{tabular}


Table 8 Names and demographic distributions of China's 56 ethnic groups (Continued)

\begin{tabular}{lll}
\hline Tajik* & 51.07 & Xinjiang, Zhejiang, Guangdong, Jiangxi, Shandong \\
Tatar* & 3.56 & Xinjiang, Guangdong, Guangxi, Beijing, Jiangsu \\
Tibetan & 6282.19 & Tibet, Sichuan, Qinghai, Gansu, Yunnan \\
Tu & 289.57 & Qinghai, Gansu, Guangdong, Yunnan, Guizhou \\
Tujia & 8353.91 & Hunan, Hubei, Guizhou, Chongqing, Zhejiang \\
Uygur & $10,069.35$ & Xinjiang, Beijing, Hunan, Guangdong, Zhejiang \\
Uzbek* & 5.67 & Xinjiang, Zhejiang, Guangdong, Beijing, Hunan \\
Va & 429.71 & Yunnan, Shandong, Guangdong, Zhejiang, Henan \\
Xibe & 190.48 & Liaoning, Xinjiang, Heilongjiang, Jilin, Inner Mongolia \\
Yao & 2796.00 & Guangxi, Hunan, Guangdong, Yunnan, Guizhou \\
Yi & 8714.39 & Yunnan, Sichuan, Guizhou, Zhejiang, Guangdong \\
Yugur* & 14.38 & Gansu, Xinjiang, Qinghai, Beijing, Shandong \\
Zhuang & $16,926.38$ & Guangxi, Yunnan, Guangdong, Zhejiang, Guizhou \\
\hline
\end{tabular}

The Sixth National Population Census of the People's Republic of China (conducted at 0:00 a.m. on November 1, 2010) "**"Denotes that ethnic groups are not analyzed as individual variables in this paper

\section{Competing interests}

The author declares that he has no competing interests.

Received: 15 July 2015 Accepted: 18 December 2015

Published online: 06 January 2016

\section{References}

Adam, C. and D. Cobham (2007). Modeling multilateral resistance in a gravity model with exchange rate regimes. The Centre for Dynamic Macroeconomic Analysis, University of St Andrews. Available at www.st-andrews.ac.uk/cdma. Accessed on 2014-4-8.

Alesina A, Spolaore E (1997) On the number and size of nations. Q J Econ 112(Nov.):1027-1056

Anderson JE, Marcouiller D (2002) Insecurity and the pattern of trade: empirical investigation. Rev Econ Stat 84:342-352 Arceneaux K, Huber GA (2007) What to do (and not to do) with multicollinearity in state politics research. State Polit Policy Q 7(1):81-101

Baldwin R, Taglioni D (2006) Gravity for dummies and dummies for gravity equations, NBER Working Paper No. 12516 Berry WD, Feldman S (1985) Multiple regression in practice. Sage Publications, London

Boisso D, Ferrantino M (1997) Economic distance, cultural distance and openness in international trade: empirical puzzles. J Econ Integrat 12:456-484

China Association of Communications and Transportation and the National Development and Reform Commission of the PRC (2001) China communications yearbook 2000. China Communications Yearbook Press, Beijing

China Association of Communications and Transportation and the National Development and Reform Commission of the PRC (2011) China communications yearbook 2010. China Communications Yearbook Press, Beijing

Cnradio, 10 November (2006) Qingzang railway transported 0.73M passengers, boosts Tibet economy (in Chinese). China National Radio (Cnradio), Beijing. Available at www.cnradio.com.cn/2004news/internal/200611/t20061110_ 504324840.html. Accessed 2013/4/15.

Combes P-P, Lafourcade M, Mayer T (2005) The trade-creating effects of business and social networks: evidence from France. J Int Econ 66(1):1-29

Deardorff AV (1998) Determinants of bilateral trade: does gravity work in a neoclassical world? In: Frankel JA (ed) The Regionalization of the World Economy. University of Chicago Press, Chicago, pp 7-22

Eaton J, Tamura A (1994) Bilateralism and regionalism in Japanese and U.S. trade and direct foreign investment patterns. J Japanese Int Econ 8:478-510

Feenstra RC (2004) Advanced international trade: theory and evidence. Princeton University Press, Princeton, NJ Felbermayr G, Jung B, Toubal F (2010) Ethnic networks, information, and international trade: revisiting the evidence. Annales d'Economie et de Statistique 97-98:41-70

Foroutan F, Pritchett L (1993) Intra-Sub-Saharan African trade: is it too little? J Afr Econ 2(May):74-105

Frankel JA, Wei S-J (1995) European integration and the regionalization of world trade and currencies: the economics and the politics. In: Eichengreen B, Frieden F, von Hagen J (eds) Monetary and fiscal policy in an integrated Europe. Springer, New York, pp 23-51

Frankel JA, Stein E, Wei S-J (1997a) Trading blocs and the Americas: the natural, the unnatural, and the super-natural. J Dev Econ 47(1):61-95

Frankel JA, Stein E, Wei S-J (1997b) Regional trading blocs in the world economic system. Institute for International Economics, Washington, DC

Guiso L, Sapienza P, Zingales L (2006) Does culture affect economic outcomes? J Econ Perspect 20:23-48

Guo R (2004) How culture influences foreign trade: evidence from the U.S. and China. J Socio-Econ 33:785-812

Guo R (2007) Linguistic and religious influences on foreign trade: evidence from East Asia. Asian Econ J 21(1):100-121 
Guo R (2009) Intercultural economic analysis: theory and method. Springer, New York Guo R (2013) Understanding the Chinese economies. Academic Press/Elsevier, Oxford Havrylyshyn O, Pritchett L (1991) European trade patterns after the transition, Policy, Research and External Affairs

Working Paper No. 74. The World Bank, Washington, DC

Head K, Disdier A (2008) The puzzling persistence of the distance effect on bilateral trade. Rev Econ Stat 90(1):37-48 Head K, Mayer T (2013) Gravity equations: workhorse, toolkit, and cookbook, CEPR Discussion Paper 9322

Heckscher EF (1919) The effect of foreign trade on the distribution of income. Ekonomisk Tidskrift 21:497-512

Helpman E (1987) Imperfect competition and international trade: evidence from fourteen industrial countries. J Jpn Int

Econ 1(Mar.):62-81

Krugman PR (1995) Growing world trade: causes and consequences. Brookings Pap Econ Activ 1:327-362

Linder SB (1961) An essay on trade and transformation. John Wiley and Sons, New York

Linders G-JM, Slangen A, de Groot H, Beugelsdijk S (2005) Cultural and institutional determinants of bilateral trade

flows, Tinbergen Institute Discussion Paper No. 074/3

Linnemann H (1966) An econometric study of international trade theory. North-Holland, Amsterdam

Markusen J (1986) Explaining the volume of trade: an eclectic approach. Am Econ Rev 76:1002-1011

Melitz J (2008) Language and foreign trade. Eur Econ Rev 52(4):667-699

NBS (National Bureau of Statistics) (2001) China statistical yearbook 2000. China Statistics Publishing House, Beijing

NBS (National Bureau of Statistics) (2011) China statistical yearbook 2010. China Statistics Publishing House, Beijing

Noland M (2005) Affinity and international trade. Working Paper Series WP 05-3. Institute for International Economics,

Washington, DC

Ohlin B (1933) Interregional and international trade. Harvard University Press, Cambridge, MA

Poncet S (2005) A fragmented China: measure and determinants of Chinese domestic market disintegration. Rev Int Econ 13(3):409-430

Pöyhönen P (1963) A tentative model for the volume of trade between countries. Weltwirtschaftliches Archiv 90(1):93-99

Rauch JE (1999) Networks versus markets in international trade. J Int Econ 48(1):7-35

Rauch JE (2001) Business and social networks in international trade. J Econ Lit 39(4):1177-1203

Rauch JE, Trindade V (2002) Ethnic Chinese networks in international trade. Rev Econ Stat 84(1):116-130

Rumbaugh T, Blancher N (2004) China: international trade and WTO accession, IMF Working Paper WP/04/36.

International Monetary Fund (IMF), Washington, DC

Simon $L J$ (2004) Detecting multicollinearity using variance inflation factors. Penn State Department of Statistics, The Pennsylvania State University.

Stewart JQ (1948) Demographic gravitation: evidence and applications. Sociometry 2:31-58

Tinbergen J (1962) An analysis of world trade flows, the Linder hypothesis, and exchange risk. In: Tinbergen J (ed) Shaping the world economy. The Twentieth Century Fund, New York

WTO (2011) World Trade 2010, prospects for 2011 (Trade growth to ease in 2011 but despite 2010 record surge, crisis hangover persists), World Trade Organization (WTO) Press/628., 7 April, . Available at: http://www.wto.org/english/ news_e/pres11_e/pr628_e.htm. Accessed 2013/4/5

Zipf GK (1946) The $\mathrm{P}^{1} \mathrm{P}^{2} / \mathrm{D}$ hypothesis: on the intercity movement of persons. Am Sociol Rev 11(6):677-686

\section{Submit your manuscript to a SpringerOpen ${ }^{\circ}$ journal and benefit from:}

- Convenient online submission

- Rigorous peer review

- Immediate publication on acceptance

- Open access: articles freely available online

- High visibility within the field

- Retaining the copyright to your article 